\title{
A CRIAÇÃO LITERÁRIA E A PRODUÇÃO EDITORIAL NO BRASIL
}

Vera Maria Tietzmann Silva ${ }^{1}$

\begin{abstract}
Resumo: Este artigo pretende mostrar a variedade da produção editorial brasileira destinada tanto ao público adulto como ao juvenil. A grande quantidade de títulos novos, como de clássicos reeditados, torna difícil ao professor decidir quais escolher para suas aulas. Os temas variam da História à fantasia, dos sentimentos íntimos às preocupações sociais. Quanto ao valor estético, as diferenças também são grandes, indo do trivial à obra-prima. Uma visão crítica é imprescindível para que se possam fazer boas escolhas.
\end{abstract}

Palavras-chave: Produção editorial brasileira; obras para adultos e jovens; temas e qualidade estética.

Um olhar sobre os catálogos das editoras brasileiras revela que existem livros para todas as idades, gostos e bolsos. Há livros simples e refinados, para leitores iniciantes ou para leitores exigentes. Nessas vitrinas que as editoras fazem circular a cada ano, o pequeno texto que acompanha a reprodução da capa funciona como um aperitivo, aguçando o desejo do leitor, antecipando o prazer que essa capa esconde e oferece. Nos catálogos juvenis reencontramos os clássicos antigos e modernos, muitas vezes com nova apresentação, ou mesmo em novas linguagens e interpretações - como as atualizações e as edições em quadrinhos (ou em mangás, hoje em moda). Estas, trabalhando com imagens, tratam de fisgar o jovem que acha fastidioso ler longos parágrafos, intermináveis capítulos; já as atualizações tratam de desafiar a argúcia dos leitores mais experientes, que se veem forçados a comparar o modelo original à sua versão renovada, num saudável exercício de leitura crítica.

Às centenas de títulos do acervo consolidado de cada grande editora, anualmente acrescentam-se dezenas mais, de autoria tanto de novos escritores como de autores conhecidos, que continuam a produzir, ou que migram de gênero

\footnotetext{
${ }_{1}^{1}$ Professora Titular aposentada da Faculdade de Letras da Universidade Federal de Goiás. É Mestre em Letras (UFG, 1984), tendo organizado e participado em coautoria de diversas coletâneas de estudos críticos. É autora, entre outros, dos livros: Literatura infantil brasileira: um guia para professores e promotores de leitura (Cânone, 2008), Leitura literária \& outras leituras: impasses e alternativas no trabalho do professor (RHJ, 2009), Dispersos \& inéditos: estudos sobre Lygia Fagundes Telles (Cânone, 2009) e Decifra-me ou te devoro! O mito grego na sala de aula (Cânone, 2017).
} 
em experiências originais de criação. O prestígio (e o mercado) conquistado pela literatura para crianças e jovens vem tornando cada vez mais frequente a incursão de nossos poetas e ficcionistas nessa modalidade de produção. As edições de antologias comemorativas ou mesmo a reedição da obra completa de escritores que completam jubileus é uma prática de várias editoras, que fazem circular livros que estavam na sombra. Carlos Drummond de Andrade, Vinicius de Moraes, Lygia Fagundes Telles e Jorge Amado são alguns desses escritores que hoje se apresentam disponíveis nas livrarias, de roupa nova e geralmente acompanhados de estudos críticos ou de cadernos didáticos destinados ao professor.

Os catálogos mostram ainda que um grande número de obras de autores estrangeiros aqui circula em tradução. Possivelmente mais na literatura infantil, e possivelmente também mais em traduções do inglês, e isso se deve à agilização do processo editorial e gráfico dos livros, uma vez adquiridos os direitos de reprodução.

Ao fazer uma consulta aos catálogos de dez ou doze editoras de prestígio, o professor constata, perplexo, que é impossível conhecer tudo, ler todos os livros. Como, então, fazer suas escolhas de leitura? Na verdade, as breves ementas que ali constam podem ajudar, mas talvez não sejam totalmente confiáveis, pois, afinal, trata-se de material de propaganda, cuja meta é vender. E será que quem escreveu esses verbetes é de fato um leitor experiente e crítico?

Para nortear a escolha sempre é possível recorrer a alguns indicadores supostamente confiáveis, como as premiações literárias e as listas das obras mais vendidas. No caso dos livros destinados à criança e ao jovem, um parâmetro seguro é a premiação anual da Fundação Nacional do Livro Infantil e Juvenil. Seus prêmios e diplomas são atribuídos pela votação de um corpo respeitável de especialistas de todo o país. Outros prêmios conceituados também existem nessa área, como o Barco a Vapor e o Jabuti.

Contudo, como os avaliadores em geral são em pequeno número (de três a cinco por banca), esses certames às vezes registram surpresas. Em 2012, por exemplo, o Jabuti de livro infantil não foi para nenhum autor brasileiro, mas para Benjamin, poema com desenhos e música, obra de um italiano residindo temporariamente no Brasil. Nesse mesmo ano, outra surpresa foi o lamentável caso 
do romance Infâmia, de Ana Maria Machado, equívoco que lançou uma sombra sobre os critérios do Jabuti, motivando alterações na forma de avaliação nos anos seguintes.

Outro indicador são as listas dos best-sellers, publicadas semanalmente em revistas de grande circulação. Essas listas contrastam bastante com os catálogos das editoras, pois, embora seja enorme o número de obras brasileiras disponíveis no mercado, quem mais vende no Brasil são os estrangeiros. São poucos os autores nacionais que entram nessas listas. Elas têm, no entanto, o mérito de revelar tendências de gosto do público leitor, que adquire obras que despertam livremente o seu interesse, sem imposição da escola.

É interessante observar que nessas listas costumam entrar também livros de apelo juvenil, mesclando aventura e mistério. Aliás, a distância entre obras orientadas para o público juvenil e o adulto tem-se estreitado cada vez mais. $\mathrm{O}$ fosso que costumava separar esses dois segmentos de leitores vem sendo cruzado por pontes que permitem não só a travessia dos jovens para o território adulto, mas também o contrário, a migração do interesse dos adultos pelas obras juvenis. Isso se deve a uma espécie de "terceira margem", onde as duas produções se encontram e confundem.

A literatura juvenil tem recorrido a técnicas narrativas mais sofisticadas envolvendo, por exemplo, a perspectiva narrativa, a construção dos personagens e a abordagem do tema, propondo, simultaneamente, reflexões de ordem filosófica, existencial ou social. Isso acontece tanto com textos nacionais como com estrangeiros. São livros que, com personagens infantis ou adolescentes, fazem o leitor refletir, na medida de seu entendimento, sobre questões humanas mais amplas. O menino do pijama listrado, de John Boyne (2007), e O dia em que Luca não voltou, de Luís Dill (2009), podem ser mencionados como obras situadas nesse entrelugar.

Essas obras limítrofes abordam questões ligadas ao cotidiano, como sequestro, violência, condutas antissociais diversas - cenas que os jornais nos mostram todos os dias com traços bem crus. Mas muitos desses livros também tematizam um outro lado, que não se ancora na realidade cotidiana, porém se volta 
para o mistério, para o inexplicável, num mergulho no passado mais remoto do ser humano. Desse mergulho, emergem das profundezas personagens e situações de um passado pré-racional - um tempo mítico de fadas e de monstros, de divindades e heróis, de lobisomens e vampiros. Sobretudo na literatura estrangeira que aqui circula em tradução, esses temas têm recebido um tratamento alegórico que recorre às raízes muito antigas, porém sempre atuais, do mito e do folclore. Essa mesma tendência pode ser observada nos filmes de cinema e nos seriados de TV, atraindo jovens e adultos indistintamente.

$\mathrm{Na}$ literatura para jovens, são representativos dessa tendência $O$ Senhor dos Anéis, de Tolkien, um clássico de fantasia dos anos 1940; a série do bruxo Harry Potter, de J. K. Rowling, já deste novo século; as histórias atualizadas de vampiros e lobisomens, de Stephanie Myers; os mitos gregos transportados para os dias de hoje, de Rick Riordan. A estrondosa receptividade desses livros motivou sua transformação em filmes de sucesso, ao mesmo tempo em que derrubou o velho mito de que os jovens não têm fôlego para uma leitura extensiva.

Paralelamente a essa temática dos livros juvenis, na literatura para adultos têm ganhado espaço as histórias de detetive que, de um tempo para cá, receberam adeptos entre escritores brasileiros - até então esse era um reduto de americanos, ingleses e franceses. Nessa área temos, por exemplo, veteranos como Marcos Rey, com novelas juvenis e também romances para adultos, e Fernando Sabino, com as três novelas para adultos enfeixadas em $A$ faca de dois gumes (1985). O silêncio da chuva (1996), de Alfredo Garcia-Roza, outro escritor dessa modalidade narrativa, levou adiante a inovação de Sabino de contrariar as expectativas do leitor deixando o conflito sem resolução no final. Entre os escritores da nova geração, destaca-se Tony Belotto, com os vários volumes protagonizados por seu detetive Bellini. Nesta década, Flávio Carneiro que, como Garcia-Roza, é professor universitário, vem sendo a grande revelação, com $A$ confissão (2006) e O livro roubado (2013), entre outros.

Mas em que, afinal, esses autores brasileiros se diferenciam dos modelos tradicionais? De um lado, eles situam suas tramas no Brasil e tomam pessoas comuns para atuarem como investigadores - nada das acrobacias de cérebros Revista de Letras JUÇARA, Caxias - Maranhão, v. 03, n. 01, p. 288 - 298, ago. 2019 | 291 
privilegiados, como os de Sherlock Holmes ou Hercule Poirot. De outro lado, esses escritores rompem com o padrão das histórias tradicionais, alterando substancialmente o modelo de personagens, o tom narrativo, o ambiente, 0 desfecho. Isso se vê também nas histórias infantojuvenis de mistério, como as novelas criadas por João Carlos Marinho que, em vez de terem um clima de suspense, apresentam um tom humorístico e caricatural.

A essas transgressões, as histórias policiais de Flávio Carneiro acrescentam dois ingredientes a mais, que se vinculam diretamente à sua atuação profissional de professor de Letras: a incursão nos domínios do fantástico e da metalinguagem. Esta, aliás, se torna bem visível nas muitas alusões a textos literários nacionais e estrangeiros. Por exemplo, seu romance $A$ carta roubada alude já no título a um conhecidíssimo conto "de mistério e raciocínio" de Edgar Allan Poe. Um leitor que tenha uma ampla bagagem cultural ou formação em Letras certamente fará uma leitura mais prazerosa de textos assim construídos.

Lado a lado com essas ficções que exploram o mistério, a fantasia ou o sobrenatural, entre os livros mais vendidos no Brasil nas últimas décadas para o público adulto, percebe-se a persistência de uma temática que percorre outro caminho, uma trilha verde e amarela, poderíamos dizer. Em vez de voltar-se ao passado nebuloso e distante do mito, dirige-se a um passado mais recente e concreto. Referimo-nos aos livros que recriam momentos da História do Brasil, como os volumes em série de Eduardo Bueno, Laurentino Gomes, Mary del Priore e Lira Neto. Motivados por situações emblemáticas - descobrimento da América e do Brasil, vinda da família real, independência, Segundo Reinado, República, Estado Novo etc - são textos atraentes que combinam, sem ranços de ufanismo, a exatidão da pesquisa histórica com os artifícios da linguagem ficcional. O sucesso desses livros parece indicar um saudável interesse do leitor brasileiro pela identidade de seu país, ao refletir criticamente, via leitura, sobre alguns momentos e alguns protagonistas de nossa história.

Aos professores e outros promotores de leitura que anseiam por seduzir os jovens leitores para a alta literatura, gostaria de dizer que não é preciso exorcizar a literatura trivial, os bestsellers: eles podem servir de trampolim para outro patamar, 
despertando a curiosidade sobre outros conteúdos ou provocando a reflexão sobre questões cruciais na vida de cada um. Eles podem cobrir o espaço intermediário ocupado pela literatura juvenil. E aqui cabe uma breve reflexão.

Mais do que nunca, os adolescentes de hoje vivem uma situação de ambiguidade. Querem antecipar comportamentos de adulto, como ter ampla liberdade para sair à noite, sem horários nem cobranças; vestir-se no rigor da moda, com roupas e acessórios de grife; iniciar a atividade sexual muito cedo, sem medir consequências; experimentar drogas lícitas e também as ilícitas, sem censura. Contudo, ao mesmo tempo, desejam permanecer indefinidamente sob a dependência econômica dos pais, que devem bancar essa sua suposta liberdade. A aspiração maior de boa parte dos jovens que vemos nas escolas é ser criança e adulto ao mesmo tempo, gozar da autonomia do adulto - o bônus dessa situação sem assumir o ônus correspondente.

Essa ambiguidade de certa forma se espelha nos livros que o mercado oferece ao público leitor juvenil. De um lado, a cômoda leitura de livros que apenas entretêm, que parafraseiam as atitudes dos adolescentes, banalizando a vida, mostrando-a superficial, sem peso nem profundidade. Fácil também a linguagem em que são escritos, transparente, referencial, sem mistérios. São livros que pouco ou nada acrescentam à bagagem cultural do leitor. É preciso, contudo, oferecer aos jovens o que há de melhor, a leitura que Ihes permite crescer intelectualmente e alcançar um patamar de leitura crítica.

Nas novelas juvenis disponíveis no mercado, as tramas parecem agrupar-se em torno de dois eixos temáticos principais: o das ações extraordinárias (histórias de mistério, de ficção científica, de aventuras) e o das vivências cotidianas (na família, na escola, no trabalho, no lazer). Nos temas do cotidiano, além das vivências com o outro, entram também questões de natureza psicológica e existencial, a vivência de cada um consigo mesmo. E aqui têm lugar garantido as velhas questões que atormentam o ser humano desde sempre e que se tornam cruciais na adolescência: a busca da própria identidade, as relações familiares e amorosas, as pulsões internas que às vezes avassalam o indivíduo dominando-o completamente, a 
inexorabilidade do destino e as incertezas do futuro. Em resumo: o sentido da vida e o sentido da morte.

Nem sempre os temas que dizem respeito aos mistérios da natureza humana são tratados na literatura juvenil brasileira com a profundidade que merecem. Muitas vezes eles recebem uma visada mais pragmática e imediatista, quando não ao estilo "autoajuda", tão em voga hoje. São as novelinhas de encomenda sobre questões que frequentam noticiários e novelas de televisão, como bulimia e anorexia; sequestro e estupro; drogas e criminalidade; sexo, DST e AIDS; gravidez na adolescência e aborto; diversidade de gênero; preconceito e inclusão; bullying e cyberbullying etc. $\mathrm{Na}$ maioria dessas publicações, o texto transforma-se em pretexto para um mal disfarçado didatismo. A "mensagem" passa ao primeiro plano, e o valor estéticoliterário que o texto poderia ter se anula. Nos catálogos, a profusão de títulos sobre esses temas, assinados pelo mesmo grupo de autores, sugere que as grandes editoras dispõem de seus "escritores de plantão", prontos a produzir seus textos assim que um novo tema polêmico entra em pauta na mídia.

Ainda assim, ocupando aquele entrelugar mencionado há pouco, às vezes nos deparamos com um texto a meio-caminho entre o didático e o literário, entre a reflexão e a autoajuda, entre o adulto e o juvenil, capaz de atrair leitores de qualquer idade, mesmo aqueles com pouca experiência de leitura. São obras apropriadas para cursos noturnos ou turmas de EJA. Esse é o caso, por exemplo, de $A$ última grande lição (1998), de Mitch Albom.

Dizíamos há pouco que as novelas juvenis apresentam uma ampla variação no quesito qualidade estética. Os temas enfocados nas novelas bem realizadas são praticamente os mesmos das novelas medíocres, porém o que as distingue são a técnica de elaboração e o uso da linguagem, que, convocando o leitor a um papel ativo diante do texto, fazem a diferença entre o banal e o artístico. O abraço (1995), de Lygia Bojunga, que já se tornou um clássico, é bem mais do que uma trama de sequestro, estupro e assassinato. É uma história que lida com um dos grandes mistérios da alma humana, a estranha sensação que todos vivenciamos de sermos divididos, de termos um outro eu. $\mathrm{O}$ amigo imaginário que tantas crianças criam atesta que essa percepção vem desde a infância. Lygia jamais facilita as coisas para 
seu leitor, nunca o subestima. Antes, exige que ele esteja com os neurônios em pleno funcionamento, com a mente alerta, que compare, tire conclusões, reflita - e que leve essa reflexão propiciada pela leitura para a sua própria experiência de vida.

Diversos autores contemporâneos seguem a linha de Lygia, que desafia o leitor a buscar as entrelinhas do texto, ao mesmo tempo em que o enreda nas malhas da emoção, permitindo-lhe um olhar novo sobre temas já desgastados. Entre as boas novelas juvenis editadas nas últimas décadas, podem citar-se as seguintes, pela ordem de lançamento no mercado.

Do outro mundo (2002), de Ana Maria Machado, por exemplo, reacende no leitor a indignação amortecida pela banalização do tema da escravatura no Brasil. Ímpar (2002), de Marcelo Carneiro da Cunha, mostra o deficiente físico por outro prisma, não como um coitado digno de pena, mas como um cidadão pleno que exige ser tratado como os demais. O fazedor de velhos (2008), de Rodrigo Lacerda, descreve de modo muito original a passagem da adolescência para a vida adulta, a constância de um amor e de uma amizade singular, bem como a formação de leitor do protagonista. O dia em que Luca não voltou, de Luís Dill (2009), lida com a questão de crianças desaparecidas por um ângulo inusitado, dando a palavra a um personagem secundário, o filho da empregada e amigo de Luca, que repassa ao leitor sua angústia e perplexidade. Diário da queda (2011), de Michel Laub, faz em relação ao Holocausto algo semelhante ao que Ana Maria Machado fizera com a escravidão, contando a história "por dentro", pela voz de um narrador cujo avô sobrevivera a Auschwitz. Menino passarinho (2012), de Maria de Regino, trabalha o espinhoso tema do menino abandonado valendo-se da delicadeza de uma metáfora, reiterada pela ilustração em todas as páginas: o menino é delicado e frágil como um passarinho que busca a segurança e o afeto.

Alguns desses livros são claramente juvenis, outros parecem exigir um leitor mais maduro, com maior experiência de vida. Com o objetivo de fazer a ponte entre a literatura juvenil e a de adultos, desde os anos 1970, a Ática edita a coleção "Para gostar de ler". Seus mais de 40 volumes trazem crônicas, contos e poemas de autores consagrados, agrupados por temas ou por gênero. 
Com o mesmo intuito, a editora Objetiva lançou em 2011 a coleção "Para ler na escola", facilitando a passagem do jovem para um patamar de maturidade leitora. Autores cuja obra ficcional ou poética tem sido tradicionalmente dirigida à criança e ao jovem, como Bartolomeu Campos Queirós e Roseana Murray, e outros que sempre escreveram para adultos, como João Ubaldo Ribeiro, Mário Quintana e João Cabral de Melo Neto, estão reunidos nessa coleção, com seus contos, crônicas e poemas. A única indicação de público-alvo está no título da coleção, que se dirige indistintamente a leitores de qualquer idade, já que na escola noturna e nos cursos de EJA os alunos costumam ser adultos.

Isso nos leva a outra constatação: muitas fichas catalográficas recusam a identificação da faixa de leitor a que se destinam. Esta é uma tendência que parece estar em vias de consolidação desde a virada para o século XXI, com a edição das obras mais recentes de Lygia Bojunga e, a partir de 2004, com 23 histórias de um viajante e outros volumes de contos de Marina Colasanti, que não apenas omitem o tipo de público-alvo, mas também adotam um visual mais sóbrio no formato e no projeto gráfico.

Simultaneamente a essa flexibilização do destinatário, os catálogos das editoras revelam uma preocupação com o encaminhamento do jovem leitor para a leitura dos grandes escritores, não só brasileiros, mas também estrangeiros. Levando em conta o propalado (e desmentido) fôlego curto dos adolescentes, diversas editoras, como a extinta Cosacnaify, a Rocco e a Projeto, por exemplo, publicaram em texto integral contos isolados ou antologias de contos de autores canônicos, como Machado de Assis, Edgar Allan Poe, Artur Azevedo, Lima Barreto, O. Henry e outros, trazendo como apelo ao público jovem o projeto gráfico dos livros, com capa e ilustrações feitas por artistas bem conhecidos da literatura infantil, como Nelson Cruz e Odilon Morais. Nessas edições, a ilustração atua como "isca" para fisgar a atenção do leitor.

A transição do juvenil para o adulto também pode ser vista em livros que combinam, sob um mesmo tema, a adaptação de textos clássicos com outros de autores da literatura infantojuvenil, uma opção inicial válida para leitores préadolescentes ("Coleção Três por Três", da Atual). Com texto integral e projeto gráfico 
artístico, também se veem volumes de contos agrupados por temas ou por estilos de época, como Histórias de carnaval, Histórias de imigrantes, Histórias do Romantismo etc, na coleção "O Prazer da Prosa", da Scipione, reunindo autores da literatura para adultos e ilustradores da literatura infantil. A "pasteurização linguística" de textos de Machado de Assis, polêmica que ocupou espaços na mídia quando proposta, porém, me parece um grave equívoco.

Entre as centenas de títulos que o mercado oferece, sem dúvida, existem textos que não valem o tempo que se despende em lê-los, assim como existe também um grande contingente de livros rasos. Mas, em meio à mediocridade, há ótimas opções de leitura, cujo valor frequentemente é referendado pelos principais prêmios literários do setor. Cabe ao professor conhecer e avaliar o que as editoras oferecem e propor aos alunos livros que thes permitam refletir sobre si mesmos e sobre seu tempo, livros cujas tramas e linguagem se apresentem como desafio, nunca como redundância e facilitação.

Abstract: This article aims to show the variety of the Brazilian editorial production, meant for both adult and young readers. The great amount of new titles and of new editions of classics makes it difficult for the teacher to decide which ones to choose for his classes. The themes range from History to fantasy, from intimate feelings to social concerns. As for asthetics, the diffences are also great: some are trite, some are masterpieces. A critical approach is required to make good choices.

Keywords: Brazilian editorial production; books for adult and young readers; themes and aesthetic quality.

\section{Referências}

ALBOM, Mitch. A última grande lição: o sentido da vida. Tradução de José J. Veiga. Rio de Janeiro: GMT, 1998.

BOYNE, John. O menino do pijama listrado. Tradução de Augusto Pacheco Calil. São Paulo: Companhia das Letras, 2007.

BOJUNGA, Lygia. O abraço. Rio de Janeiro: AGIR, 1995.

CARNEIRO, Flávio. A confissão. Rio de Janeiro: Rocco, 2006.

. O campeonato. Rio de Janeiro: Rocco, 2009.

. O livro roubado. Rio de Janeiro: Rocco, 2013.

Revista de Letras JUÇARA, Caxias - Maranhão, v. 03, n. 01, p. 288 - 298, ago. 2019 | 297 
COLASANTI, Marina. 23 histórias de um viajante. São Paulo: Global, 2004.

CUNHA, Marcelo Carneiro da. Ímpar. Porto Alegre: Projeto, 2002.

D’ANGELO. Biagio. Benjamin: poema com desenhos e música. II. Thaís Beltrame. São Paulo: Melhoramentos, 2011.

DILL, Luís. O dia em que Luca não voltou. São Paulo: Companhia das Letras, 2009.

GARCIA-ROZA, Alfredo. O silêncio da chuva. São Paulo: Companhia das Letras, 1996.

LACERDA, Rodrigo. O fazedor de velhos. São Paulo: Cosacnaify, 2008.

LAUB, Michel. Diário da queda. São Paulo: Companhia das Letras, 2011.

MACHADO, Ana Maria. Do outro mundo. São Paulo: Ática, 2002. . Infâmia. São Paulo: Alfaguara, 2011.

REGINO, Maria de. Menino passarinho. Belo Horizonte: RHJ, 2012.

SABINO, Fernando. A faca de dois gumes. Rio de Janeiro: Record, 1985.

Data da Submissão: 06/05/2019

Data da Aprovação: 18/07/2019 